\title{
Further Studies on the P-450 Difference Spectra induced by Various Compounds in Liver Microsomes from 3-Methylcholanthrene Treated Rats
}

\author{
Tetsuya Kamataki, Masakazu Shimokawa, and Haruo Kitagawa \\ Department of Biochemical Pharmacology, Faculty of Pharmaceutical Sciences, \\ University of $\mathrm{Chiba}^{1}$
}

(Received June 7, 1972)

\begin{abstract}
Substrate induced difference spectra in microsomes from 3-methylcholanthrene treated rats were investigated using substrates which cause type I difference spectrum in microsomes from control rats. It was found that $\alpha, \alpha^{\prime}$-dipyridyl showed only type II spectrum, whereas SKF 525-A and ethylmorphine produced type I spectra. Additionally, hexobarbital, aminopyrine and imipramine produced type I spectra when they were used by rather low concentrations but type II spectra were induced by high concentrations of them. $\alpha, \alpha^{\prime}$-Dipyridyl caused type II spectrum when microsomes from control rats were treated with phospholipase C. The type II spectrum of $\alpha, \alpha^{\prime}$-dipyridyl in 3-methylcholanthrene-induced microsomes was increased by treatment with phospholipase $\mathrm{C}$.

Moreover, $\alpha, \alpha^{\prime}$-dipyridyl showed type II spectrum in microsomes from control rats when SKF 525-A, which has a high affinity to combine with type I binding site of P-450, was added into reference and sample cuvettes.

From above data, the authors concluded that most of type I compounds could combine with both type I and type II binding sites, and discussed on the properties of type $I$ and type II binding sites.
\end{abstract}

\section{Introduction}

Drugs have been classified into two groups depending upon whether they form type I or type II difference spectra when they combine with microsomal hemoprotein (P-450). In rat and rabbit liver microsomes, hexobarbital, aminopyrine and SKF 525-A cause type I difference spectra but aniline and nicotinamide cause type II spectra. ${ }^{2-4)}$ Recently, Schenkman, et al. $\left.{ }^{5}\right)$ and the authors ${ }^{6,7)}$ reported that hexobarbital showed type II difference spectrum when it was added into microsomes treated with 3-methylcholanthrene, whereas Shoeman, et al. ${ }^{8)}$ and Kato, et al. ${ }^{9)}$ reported that treatment with 3-methylcholanthrene reduced the type I difference spectrum. It was of interest for the authors to clarify these phenomena. Moreover, to prove that a type I substrate combines with both type I and type II binding sites, some spectral studies were performed using $\alpha, \alpha^{\prime}$-dipyridyl as substarte.

\section{Material and Method}

Male rats of Wistar strain weighing about $100 \mathrm{~g}$ starved for 15 to $18 \mathrm{hr}$ were used. 3-Methylcholanthrene in corn oil was given to the rats by $40 \mathrm{mg} / \mathrm{kg}$ intraperitoneally $48 \mathrm{hr}$ prior to sacrifice. Control rats were given corn oil by $1 \mathrm{ml}$ per $100 \mathrm{~g}$ of body weight intraperitoneally. Rats were killed by decapi-

1) Location: 1-33, Yayoi-cho, Chiba-shi, Chiba.

2) H. Remmer, J.B. Schenkman, R.W. Estabrook, H.A. Sasame, J.R. Gillette, D.Y. Cuoper, S. Narashimhulu, and O. Rosenthal, Mol. Pharmac., 2, 187 (1966).

3) Y. Imai and R. Sato, Biochem. Biophys. Res. Commun., 22, 620 (1966).

4) J.B. Schenkamn, H. Remmer, and R.W. Estabrook, Mol. Pharmac., 3, 113 (1967).

5) J.B. Schenkman, H. Greim, M. Zange, and H. Remmer, Biochem. Biophys. Acta, 171, 23 (1969).

6) H. Kitagawa, K. Koyama, and T. Kamataki, Proc. of the 88th Meeting of Pharmac. Soc. of Japan, Nagoya on April, 1969.

7) T. Kamataki, H. Fukazawa, and H. Kitagawa, Yakugaku Zasshi, 91, 142 (1971).

8) D.W. Shoeman, M.D. Chaplin, and G.J. Mannering, Mol. Pharmac., 5, 412 (1969).

9) R. Kato, A. Takanaka, and M. Takayanagi, J. Biochem., 68, 395 (1970). 
tation, and the livers were perfused with $1.15 \% \mathrm{KCl}$ solution in situ to remove blood. The livers were removed and immediately placed in ice-cold $1.15 \% \mathrm{KCl}$ solution. All subsequent procedures were performed below $4^{\circ}$. The livers were weighed and minced with scissors. The liver-mince was then homogenized with three volumes of the $\mathrm{KCl}$ solution in a motor-driven Potter homogenizer using a Teflon pestle. The homogenate was then centrifuged at $9000 \times \boldsymbol{g}$ for $20 \mathrm{~min}$ and the resultant supernatant fraction without fatty layer at the top of the centrifuge tube was recentrifuged at $105000 \times \boldsymbol{g}$ for $1 \mathrm{hr}$ in a HITACHI preparative ultracentrifuge, Model $65 \mathrm{P}$, to prepare microsomal pellet. The microsomal pellet was resuspended in $0.1 \mathrm{M}$ phosphate buffer $\mathrm{pH} 7.5$ and employed for the measurements. Cytochrome P-450 in liver microsomes was determined essentially as described by Omura and Sato. ${ }^{10)}$ Microsomal protein was determined according to the method of Lowry, et al. ${ }^{11)}$ Difference spectra were obtained with a HITACHI recording spectrophotometer, Model EPS-3T, with a integrating sphare accesory. Substrates employed for obtaining difference spectra were hexobarbital- Na $(0.125-10 \mathrm{~mm})$, aminopyrine $(0.01-8 \mathrm{~mm})$, SKF $525-\mathrm{A}-\mathrm{HCl}(0.01-$ $0.1 \mathrm{~mm})$, imipramine- $\mathrm{HCl}(0.01-8 \mathrm{~mm})$ and $\alpha, \alpha^{\prime}$-dipyridyl $(0.5-2 \mathrm{~mm})$. Maximal concentrations of the substrate in this study were lower concentrations than those to agglutinate or crystallize the substrates in the media. Treatment of microsomes with phospholipase $\mathrm{C}$ was performed by the method of Chaplin and Mannering ${ }^{12)}$ except that phospholipase $\mathrm{C}$ was added by one to two unit per $\mathrm{mg}$ of microsomal protein.

\section{Result}

\section{Effect of 3-Methylcholanthrene on the P-450 Difference Spectra induced by Type I Compounds}

As shown in Fig. 1-a, $\alpha, \alpha^{\prime}$-dipyridyl-induced P-450 difference spectrum was type $\mathrm{I}$ in microsomes from control rats, which had an absorption peak at about $390 \mathrm{~m} \mu$ and a trough at about $425 \mathrm{~m} \mu$, however, it produced only type II difference spectrum having a peak at about $425 \mathrm{~m} \mu$ and a trough at about $390 \mathrm{~m} \mu$ in microsomes from 3 -methylcholanthrene treated rats at any concentrations (Fig. 1-b). Hexobarbital also induced type I spectrum in microsomes from control rats (Fig. 2-a), and this was the same as previously described. ${ }^{2-4}$ ) In microsomes from 3-methylcholanthrene treated rats, rather low concentrations of it induced small but clear type I spectrum which had a peak at about $405 \mathrm{~m} \mu$ and a trough at about $430 \mathrm{~m} \mu$, however, type II difference spectrum, peak at about $420 \mathrm{~m} \mu$ and a trough at about $380 \mathrm{~m} \mu$, was observed by its high concentrations (Fig. 2-b). Aminopyrine and imipramine gave similar results. On the other hand, SKF 525-A induced only type I spectrum if microsomes from control and 3-methylcholanthrene treated rats were employed, at any concentrations of the substrate, but the magnitude of the type I spectrum was reduced by about 30 to $40 \%$ by treatment with 3 -methylcholanthrene (Fig. 3-a, Fig. 3-b). Maximal concentrations of SKF 525-A was lower than those of the others, since the higher concentrations of it could not be employed for its insolubility in the media. Ethylmorphine also gave similar results in wide various concentrations, 0.01 to $8 \mathrm{~mm}$.

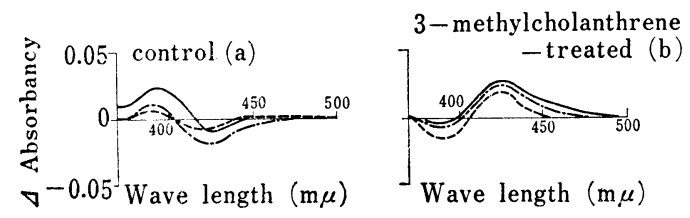

Fig. 1. P-450 Difference Spectra induced by Various Concentrations of $\alpha, \alpha^{\prime}$-Dipyridyl

$$
\begin{aligned}
& \text { in control group: microsomal protein, } 3.33 \mathrm{mg} / \mathrm{ml} \\
& \text { P-450, } 0.690 \mathrm{~m} \mu \text { mole } / \mathrm{mg} \text { protein } \\
& \text { in 3-methylcholanthrene-treated group: microsomal } \\
& \text { protein, } 1.78 \mathrm{mg} / \mathrm{ml} \\
& \text { P-450, } 1.190 \mathrm{~m} \mu \mathrm{mole} / \mathrm{mg} \text { protein } \\
& -1.0 .5 \mathrm{~mm} ; \\
& -: 2.0 \mathrm{~mm}
\end{aligned}
$$

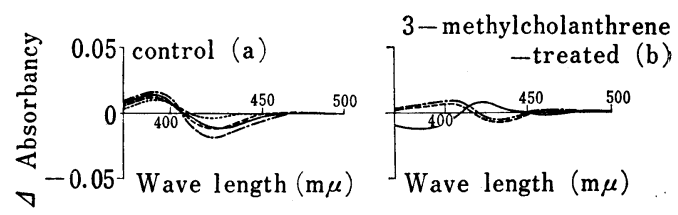

Fig. 2. P-450 Difference Spectra induced by Various Concentrations of Hexobarbital

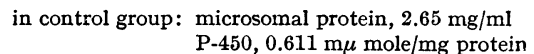

in 3-methylcholanthrene-treated group: microsomal protein, $3.20 \mathrm{mg} / \mathrm{ml}$

P-450, $1.353 \mathrm{~m} \mu \mathrm{mole} / \mathrm{mg}$ protein

$0.125 \mathrm{mx} ; \quad---: 0.5 \mathrm{~mm}$

10) T. Omura and R. Sato, J. Biol. Chem., 239, 2370 (1964).

11) O.H. Lowry, N.J. Rosebrough, A.L. Farr, and R.J. Randall, J. Biol. Chem., 193, 265 (1951).

12) M.D. Chaplin and G.J. Mannering, Mol. Pharmac., 6, 631 (1970). 


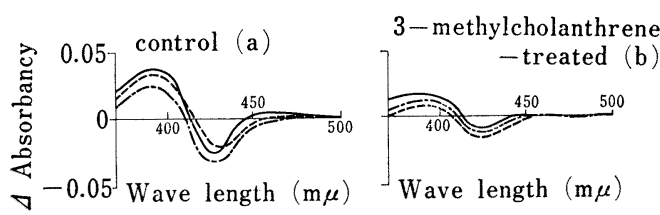

Fig. 3. P-450 Difference Spectra induced by

Various Concentrations of SKF 525-A

in control group: microsomal protein, $2.62 \mathrm{mg} / \mathrm{ml}$ $\mathrm{P}-450,0.609 \mathrm{~m} \mu \mathrm{mole} / \mathrm{mg}$ protein

in 3-methylcholanthrene-treated group: microsomal protein, $1.41 \mathrm{mg} / \mathrm{ml} \quad \mathrm{P}-450,1.014 \mathrm{~m} \mu$ mole $/ \mathrm{mg}$ protein

$--: 0.01 \mathrm{~ms} ; \quad--: 0.05 \mathrm{~ms} ; \quad-: 0.10 \mathrm{~ms}$
TABLE I. Effects of 3-Methylchlolanthrene on Stability of P-450 against Treatment with Phospholipase C

\begin{tabular}{cc}
\hline P-450 remained after \\
Microsomes & $\begin{array}{c}\left.\text { treatment with phospholipase } \mathrm{C}^{c}\right) \\
\% \pm \text { S.E. }(n=3)\end{array}$
\end{tabular}

\begin{tabular}{lc}
\hline $\begin{array}{c}\text { Control } \\
\text { (oil treated) }\end{array}$ & $44.17 \pm 9.85$ \\
$\begin{array}{c}\text { 3-Methylcholanthrene- } \\
\text { treated }\end{array}$ & $63.53 \pm 7.21$
\end{tabular}

a) Total P-450 remained in microsomes treated with phospholipase $C$, centrifuged and washed once as described by chaplin and Mannering. ${ }^{12}$ )

\section{Effects of Phospholipase C Treatment on P-450 and $a, \alpha^{\prime}$-Dipyridyl-induced P-450 Difference Spectrum in Microsomes from Control and 3-Methylcholanthrene Treated Rats}

Effects of phospholipase $\mathrm{C}$ treatment on the stability of microsomal P-450 from control and 3-methylcholanthrene treated rats were studied. As shown in Table 1, P-450 in 3-methylcholanthrene-induced microsomes was not lost compared to that in control microsomes, so that it was assumed that 3-methylcholanthrene-induced P-450 is more stable than the another one to the treatment. 3-Methylcholanthrene-induced P-450 has been shown to be more stable against various treatments than those in microsomes from control and phenobarbital treated rats. ${ }^{13)}$ Our result and those findings may suggest that P-450 induced by 3-methylcholanthrene has different property in its hydrophobic region from the others. Moreover, effects of phospholipase $\mathrm{C}$ treatment on $\mathrm{P}-450$ difference spectrum induced by $\alpha, \alpha^{\prime}$-dipyridyl were measured using control and 3-methylcholanthrene treated microsomes (Fig. 4). The type I difference spectrum in control microsomes was increased with the concentrations of $\alpha, \alpha^{\prime}-$ dipyridyl, however, type II spectrum was observed when the microsomes were treated with

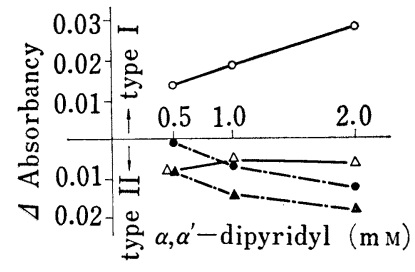

Fig. 4. Effects of phospholipase C (Pase C) Treatment on Difference Spectrum induced by $\alpha, \alpha^{\prime}-$ Dipyridyl with 3-Methylchloanthrene-pretreated and Control Microsomes

Method for obtaining phospholipase $\mathrm{C}$ treated microsomes is described in Table $\mathrm{I}$.

in control: microsomal protein $\{2.98 \mathrm{mg} / \mathrm{ml}$ (untreated)

P-450 $0.948 \mathrm{~m} \mu \mathrm{mole} / \mathrm{mg}$ protein (untreated) $\mathrm{P}-450\left\{\begin{array}{l}0.948 \mathrm{~m} \mu \mathrm{mole} / \mathrm{mg} \text { protein (untreated) } \\ 1.012 \mathrm{~m} \mu \mathrm{mole} / \mathrm{mg} \text { protein (Pase C treated) }\end{array}\right.$ in 3-methylcholanthrene-treated: microsomal protein $\{1.75 \mathrm{mg} / \mathrm{ml}$ (untreated) P. $0.62 \mathrm{mg} / \mathrm{ml}$ (Pase C treated) P-450 $\left\{\begin{array}{l}1.036 \mathrm{~m} \mu \mathrm{mole} / \mathrm{mg} \text { protein (untreated) } \\ 1.737 \mathrm{~m} \mu \mathrm{mol} / \mathrm{mg} \text { protein }\end{array}\right.$ $\mathrm{mg}$ protein (Pase $\mathrm{C}$ treateed)

$-\bigcirc-$ : oil (OD390-425m $\mu$ )

-...-..: oil + Pase C (OD420-383m $\mu$ )

$\triangle-$ : 3-methhylcholanthrene (OD425-390m $\mu$ )

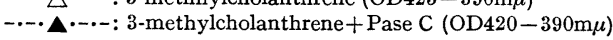

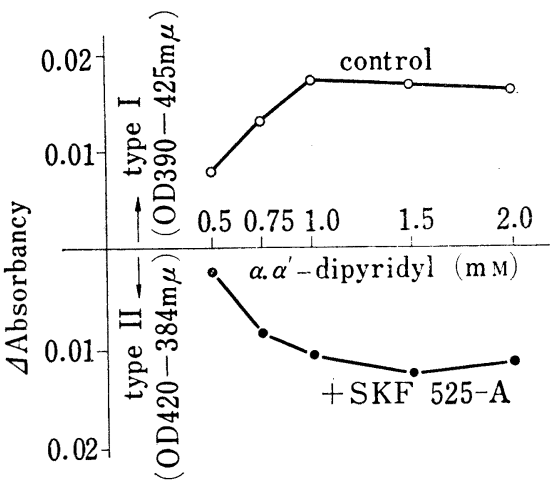

Fig. 5. Effect of SKF 525-A on Difference Spectrum induced by $\alpha, \alpha^{\prime}$-Dipyridyl in Control Microsomes

SKF 525-A-HCl (0.1 mM) was added into both reference and sample cuvettes, then $\alpha, \alpha^{\prime}$-dipyridyl was added into sample cuvette. Microsomal protein and content of P-450 were $2.72 \mathrm{mg} / \mathrm{ml}$ and $0.974 \mathrm{~m} \mu$ mole/mg protein, respectively. 
phospholipase C. In 3-methylcholanthrene-induced microsomes, treatment with phospholipase $\mathrm{C}$ enhanced the type II spectrum. These findings may suggest that loss of P-450 caused by phospholipase $\mathrm{C}$ treatment was accompanied with degradation of type I binding site. For the purpose to confirm the hypothesis that $\alpha, \alpha^{\prime}$-dipyridyl combines with both type I and type II binding sites, the following experiment was scheduled. SKF 525-A, which combines strongly with type I binding site, ${ }^{4)}$ was added into both reference and sample cuvettes to prevent the type I binding site from binding with $\alpha, \alpha^{\prime}$-dipyridyl. The effect of SKF 525-A on $\alpha, \alpha^{\prime}$-dipyridyl-induced P-450 difference spectrum was shown in Fig. 5 . As was expected, type I difference spectrum in microsomes from control rats was changed into type II by SKF 525-A. Therefore, it was concluded that there are two binding sites in microsomal P-450 (or two species of P-450), and that most of type I compounds can bind not only with type I binding site but also with type II binding site.

\section{Discussion}

The authors obtained some facts to support the following hypothesis that type I compounds combine not only with type I binding site but also, to a lesser degree, with type II binding site, and that only type I spectrum would be seen when a substrate combines more preferentially with type I binding site than type II binding site since the type I and type II binding spectra are near mirror images and can cancel eath other. In accordance with this. hypothesis, $\alpha, \alpha^{\prime}$-dipyridyl appeared to be bound with both type I and type II binding sites, and was a good material to prove the hypothesis. $\alpha, \alpha^{\prime}$-Dipyridyl seemed to be able to bind readier with type II binding site than the others employed in this study. The amount bound to the type II binding site might be followed by aminopyrine, hexobarbital and imipramine. Although SKF 525-A and ethylmorphine did not show any type II spectra in this study, the fact may not always represent that these substrates do not combine with type II binding site, since SKF 525-A produced only type II spectrum in human liver microsomes. ${ }^{14)}$ Imai, et al. ${ }^{13)}$ have recently studied on the effects of 3-methylcholanthrene on ethylisocyanideinduced P-450 difference spectrum, and speculated that 3-methylcholanthrene affects the interaction of lipids with P-450 heme and makes the binding more tight. However, it seems. possible to explain the effect of 3-methylcholanthrene in another way. It is likely that aniline combines with hydrophilic sixth ligand of P-450 heme since carbonmonoxide competes with aniline for the sixth ligand of P-450.4) Additionally, 3-methylcholanthrene increases magnitude of P-450-aniline binding spectrum as well as activity of aniline hydroxylase. Therefore, 3-methylcholanthrene may increase P-450 having more hydrophilic binding site than that in control microsomes. Furthermore, there have been some reports supporting this hypothesis, ${ }^{12,15}$ Chaplin and Mannering ${ }^{12)}$ speculated that type I and type II binding sites. differ and that the type I binding site is associated with membrane phospholipids, since the type I binding spectra were markedly reduced by the treatment of microsomes with phospholipase C. On the hydrophobicity of microsomal membrane, Eling and Di Augustine ${ }^{16)}$ reported that treatment of microsomes with phospholipase $\mathrm{C}$ produced significant decrease in the hydrophobicity of microsomal protein.

Then, it may be possible to assume that type I binding site is localized in the hydrophobic region of P-450 which is associated with membrane phospholipids. Recently, besides these, Ariyoshi and Takabatake reported on the contents of microsomal phospholipids that treatment of rats with 3 -methylcholanthrene significantly reduced total phospholipids. ${ }^{17)}$ From

14) T. Kamataki, M. Kitada, and H. Kitagawa, Chem. Pharm. Bull. (Tokyo), 19, 1749 (1971).

15) K.C. Leibman and R.W. Estabrook, Mol. Pharmac., 7, 26 (1971).

16) T.E. Eling and R.P.Di Augustine, Biochem. J., 123, 539 (1971).

1i) T. Ariyoshi and E. Takabatake, Proc. of the third Symp. on Drug Metabolism and Action, Fukuoka, 1971. 
above findings, it is very likely that 3 -methylcholanthrene-induced P-450 is associated with smaller amount of phospholipids, and thus it is stable for the treatments with lipases.

The hypothesis that type I compounds can combine with both type I and type II binding sites depending on their concentrations may well explain the nonlinearity of the Lineweaver-Burk's plots in kinetic study of substrate difference spectra. 